\title{
Metabolic imaging of in vivo myocardium
}

\author{
Charles S Springer ${ }^{1,2^{*}}$, Craig S Broberg ${ }^{3,2}$, William D Rooney ${ }^{1,2}$ \\ From 18th Annual SCMR Scientific Sessions \\ Nice, France. 4-7 February 2015
}

\section{Background}

The equilibrium cellular water efflux rate constant $\left[\mathrm{k}_{\mathrm{io}}\right.$; mean water lifetime inverse] from contrast agent [CA]enhanced MRI measures on-going cellular $\mathrm{Na}^{+}, \mathrm{K}^{+}$-ATPase activity [turnover]. Good literature [4 different labs] agreement shows substantial $k_{\text {io }}$ decreases in myocardial ischemia, hypertension, or infarct regions (Table). The 3 methods used differ in extracellular ("outside") $\mathrm{CA}_{\mathrm{o}}$ level manipulation to change the MR shutter-speed relative to $k_{\text {io }}$ and the MR exchange condition reached: A) $C_{\text {o }}$ steady-state, slow-exchange-regime; $\mathrm{B}) \mathrm{CA}_{\mathrm{o}}$ titration, fastexchange-regime [FXR]; and C) $\mathrm{CA}_{\mathrm{o}}$ wash-out, FXR. The independent intracellular volume fraction $[\mathrm{ICV}]$ - cell density $\bullet$ volume product and $\approx 1$ - ECV [extracellular volume fraction] - also decreases in pathology. We hypothesize that $k_{\text {io }}$ mapping shows metabolic compromise most effectively. We report initial experience with tissue near a repaired ventricular septal defect [VSD].

\section{Methods}

We acquired serial $1.5 \mathrm{~T}^{1} \mathrm{H}_{2} \mathrm{O} \mathrm{T}_{1}$-weighted data from a 27 yo male before and 3 times after a bolus IV $0.15 \mathrm{mmol} / \mathrm{kg}$ CA [Omniscan] injection. Quantitative Look-Locker $\mathrm{T}_{1}$ measurements [non-selective inversion, 21 recovery times] imaged an $8 \mathrm{~mm}$ slice with a mid-ventricular short axis location inferior to the VSD patch. Method $\mathrm{C}\left(\mathrm{CA}_{\mathrm{o}}\right.$ washout, FXR) determined $k_{\text {io }}$ and ICV values in six LV wall segments.

\section{Results}

The Figure shows a post-CA $\mathrm{T}_{1}$-w image: the endo- and epicardial LV wall edges as bright orange and green, respectively [light orange circle, an LV ROI]. Segmental ICV and $k_{\text {io }}$ values are given (yellow). Segments S5 and S6 comprise the septum. The ICV values for segments S1 - S4 are reasonable for normal myocardium (Table). Thus, we

'Advanced Imaging Research Center, Oregon Health \& Science University, Portland, OR, USA

Full list of author information is available at the end of the article have indicated (*) a control myocardial $\mathrm{k}_{\mathrm{io}}$ value $\left[5 \mathrm{~s}^{-1}\right.$, Table], since the CA wash-out data quantity [3 points] and quality from these normal myocardium segments yielded insufficient precision. Interestingly, the $\mathrm{k}_{\mathrm{io}}$ value is reduced $\left[4.5 \mathrm{~s}^{-1}\right]$ in segment $\mathrm{S} 6$, and dramatically so $\left[1.7 \mathrm{~s}^{-1} ; 66 \% \downarrow\right]$ in segment S5, immediately inferior to the VSD patch.

\section{Conclusions}

The $k_{i o}$ biomarker is a sensitive measure of on-going myocardial metabolic activity. Our result suggests that tissue nearby a VSD patch can be, or become, metabolically compromised.

The ultimate goal is pixel-wise $k_{\text {io }}$ and ICV maps. [Here, nominal voxels are $2 \times 2 \times 8 \mathrm{~mm}^{3}=32 \mu \mathrm{L}$.] For this, one needs data with good $\mathrm{S} / \mathrm{N}$ and more than 3 wash-out points. Also, method $\mathrm{C}$ has systematic error absent in methods A and B, which cannot be used for humans. It assumes the $\mathrm{CA}_{\mathrm{o}}$ concentration equals that of $\mathrm{CA}_{\mathrm{p}}$ [in plasma] during wash-out. This is invalid for finite CA intravasation kinetics, which may be particularly slow in myocardial lesions due to common reduced

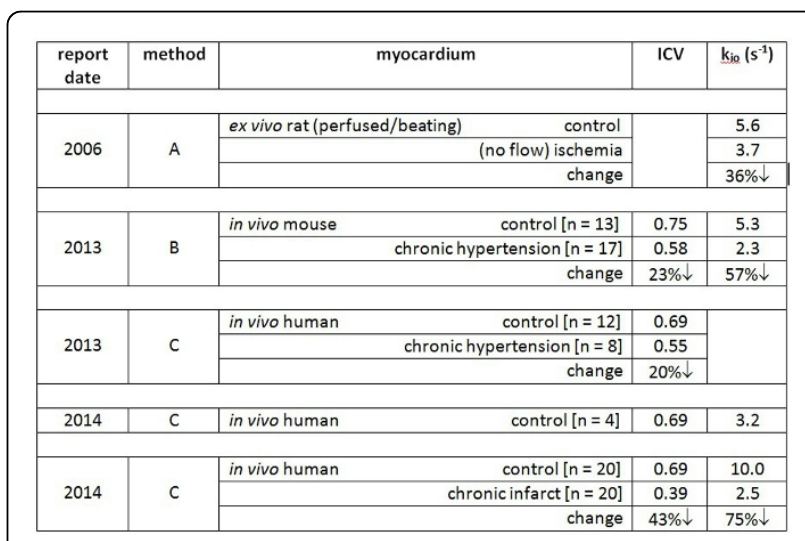

Figure 1 Literature reports of active trans-membrane water cycling $\left[\mathrm{k}_{\mathrm{i}}\right]$ and intracellular volume fraction [ICV] values in normal and pathological myocardia. 


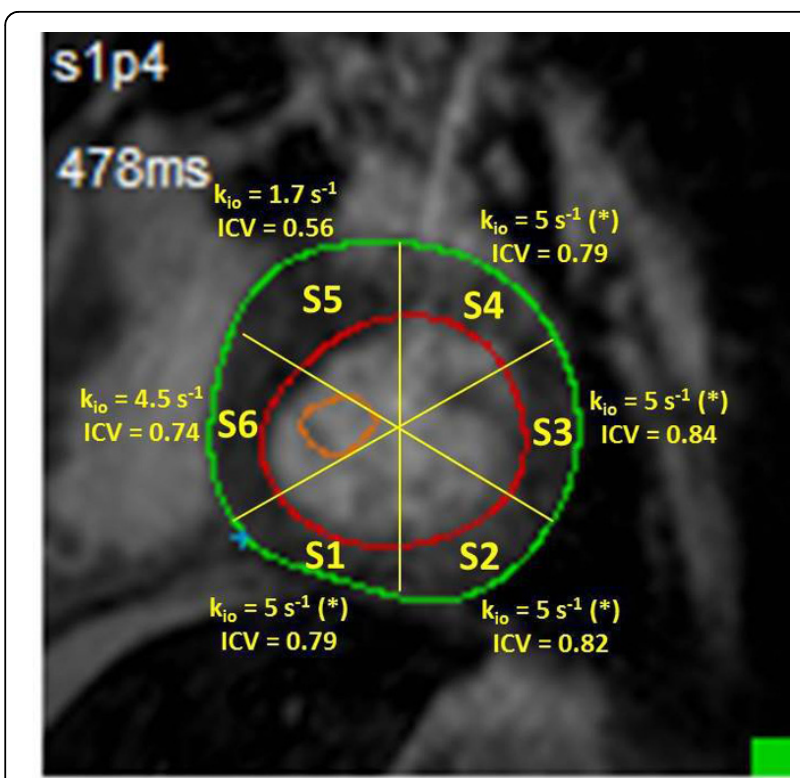

Figure 2 Short axis $T_{1}-w$ image slice inferior to VSD patch. The $k_{i o}$ and ICV values of six LV wall segments are given. $k_{i o}$ and ICV are reduced (66\% and $30 \%$, respectively) in segment \$5,immediately below the patch.

vascularization. Possible $\mathrm{k}_{\mathrm{io}}$ and ICV underestimations can be corrected using $\mathrm{K}^{\text {trans }}$ [the CA extravasation transfer constant] from the bolus tissue wash-in timecourse to calculate the CA intravasation rate constant.

\section{Funding}

NIH: RO1-NS040801.

\section{Authors' details}

'Advanced Imaging Research Center, Oregon Health \& Science University, Portland, OR, USA. ${ }^{2}$ Knight Cardiovascular Institute, Oregon Health \& Science University, Portland, OR, USA. ${ }^{3}$ Division of Cardiovascular Medicine, Oregon Health \& Science University, Portland, OR, USA.

Published: 3 February 2015

\section{doi:10.1186/1532-429X-17-S1-P25}

Cite this article as: Springer et al:: Metabolic imaging of in vivo myocardium. Journal of Cardiovascular Magnetic Resonance 2015 17(Suppl 1): P251.

\section{Submit your next manuscript to BioMed Central} and take full advantage of:

- Convenient online submission

- Thorough peer review

- No space constraints or color figure charges

- Immediate publication on acceptance

- Inclusion in PubMed, CAS, Scopus and Google Scholar

- Research which is freely available for redistribution 